\title{
Propranolol therapy for infantile hemangioma is less toxic but longer in duration than corticosteroid therapy
}

\author{
Kathryn Sawa MD¹, Arjang Yazdani MD FRCSC ${ }^{1}$, Michael J Rieder MD PhD FRCPC ${ }^{2,3}$, Guido Filler MD PhD FRCPC ${ }^{2,3,4}$
}

K Sawa, A Yazdani, MJ Rieder, G Filler. Propranolol therapy for infantile hemangioma is less toxic but longer in duration than corticosteroid therapy. Plast Surg 2014;22(4):233-236.

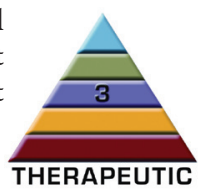

BACKGROUND: Infantile hemangioma is the most common benign, self-limiting tumour of childhood. Treatment is reserved for hemangiomas that obstruct vital structures or cause significant disfigurement. Traditionally, corticosteroids have been the medical treatment of choice. Since 2008, however, propranolol has been rapidly adopted as an effective pharmacological treatment for infantile hemangioma. Published data regarding the long-term side effects of propranolol are currently lacking.

OBJECTIVE: To describe the long-term effects of propranolol and corticosteroids on anthropometric measurements (height, body mass index [BMI]) and blood pressure in children.

METHODS: A prospective database analysis of all infantile hemangioma patient visits to the pediatric vascular abnormality clinic at the authors' institution between October 2007 and February 2012 was performed. Anthropometric measures (height and BMI) and blood pressure were analyzed.

RESULTS: A total of 290 visits (119 patients) to the pediatric vascular abnormality clinic were reviewed. Of these, 18 patients received medical treatment and their anthropometry was analyzed. BMI percentile increased significantly in patients treated with corticosteroids $(\mathrm{P}=0.0039)$. Corticosteroid treatment also resulted in a significant decrease in height percentile $(\mathrm{P}=0.0078)$. Anthropometric measures did not cross percentiles in children treated with propranolol. A significant decrease in systolic blood pressure was noted in the propranolol group $(\mathrm{P}=0.03)$, but no hypotensive values were recorded. Median treatment duration was significantly longer when patients received propranolol ( 372 versus 133 days; $\mathrm{P}=0.0033$ ). CONCLUSION: Propranolol for the treatment of infantile vascular abnormalities does not share the unfavourable effects on patient anthropometry that corticosteroids exhibit; however, a longer duration of therapy is required.

Key Words: Hemangioma; Multidisciplinary clinic, Prednisolone; Prednisone; Propranolol; Surgical treatment
The vast majority of vascular anomalies of infancy and childhood 1 can be classified as hemangioma or vascular malformation (1). Infantile hemangiomas ( $\mathrm{IHs}$ ), characterized by proliferating endothelial cells, are the most common benign vascular malformations observed in children. They often present a few weeks after birth with a rapid proliferating phase, followed by a period of quiescence and, finally, involution (2). Given this characteristic natural history, the majority of hemangiomas do not require treatment. Pharmacological therapy with corticosteroids or interferon-alpha-2a is indicated for lesions that threaten vital function or are grossly deforming (1). More recently, two new developments have had a significant impact on the management of IHs, namely the development of multidisciplinary clinics and the introduction of the beta-blocker propranolol as a therapeutic option (2). A multidisciplinary clinic provides many advantages, including effective communication among care providers, more

\section{Le traitement au propranolol est moins toxique, mais plus long que la corticothérapie pour traiter l'hémangiome infantile}

HISTORIQUE : L'hémangiome infantile est la principale tumeur
bénigne autolimitative de l'enfance. Le traitement est réservé aux
hémangiomes qui obstruent des structures vitales ou provoquent une
importante défiguration. La corticothérapie était privilégiée, mais à
compter de 2008, le propranolol a rapidement été adopté en raison de
son efficacité. Il n'y a pas de données publiées sur les effets à long terme
du propranolol. OBJECTIF : Décrire les effets à long terme du propranolol et des corticoïdes sur les mesures anthropométriques (taille, indice de masse corporelle [IMC]) et la tension artérielle chez les enfants.

MÉTHODOLOGIE : Les chercheurs ont effectué une analyse prospective des bases de données de toutes les visites de patients à la clinique pédiatrique d'anomalies vasculaires de l'établissement des auteurs en raison d'un hémangiome infantile entre octobre 2007 et février 2012. Ils ont analysé les mesures anthropométriques (taille et IMC) et la tension artérielle.

RÉSULTATS : Les chercheurs ont examiné 290 visites (119 patients) à la clinique pédiatrique d'anomalies vasculaires. De ce nombre, 18 patients ont reçu un traitement médical. Les chercheurs ont évalué leurs mesures anthropométriques. Le percentile d'IMC a augmenté de manière significative chez les patients sous corticothérapie $(\mathrm{P}=0,0039)$. La corticothérapie s'associait également à une diminution importante du percentile de taille $(\mathrm{P}=0,0078)$. Par contre, les mesures anthropométriques ne traversaient pas les percentiles chez les enfants traités au propranolol. Leur tension artérielle systolique était beaucoup plus faible $(\mathrm{P}=0,03)$, mais aucune valeur hypotensive n'a été enregistrée. Par ailleurs, la durée médiane du traitement était considérablement plus longue chez les patients qui prenaient du propranolol (372 jours au lieu de 133; $\mathrm{P}=0,0033)$.

CONCLUSION : Pour soigner les anomalies vasculaires des enfants, le propranolol n'a pas les mêmes effets défavorables sur l'anthropométrie que les corticoïdes. Cependant, le traitement est plus long.

${ }^{1}$ Department of Surgery, Division of Plastic Surgery, Western University; ${ }^{2}$ Department of Paediatrics, Children's Hospital at London Health Science Centre, Western University; ${ }^{3}$ Department of Medicine; ${ }^{4}$ Department of Pathology and Laboratory Medicine, Western University, London, Ontario

Correspondence: Dr Guido Filler, Department of Paediatrics, Children's Hospital, London Health Sciences Centre, Western University, 339 Windermere Road, London, Ontario N6G 2V4. Telephone 519-685-8377, e-mail guido.filler@lhsc.on.ca 
TABLE 1

Anatomical distribution of infantile hemangiomas in patients seen at the Children's Hospital, London Health Sciences Centre (London, Ontario) from October 2007 to February 2012

\begin{tabular}{lc}
\hline Anatomical location & \\
\hline Face & $60(50.4)$ \\
Other head & $16(13.4)$ \\
Pharynx & $1(0.9)$ \\
Torso & $22(18.5)$ \\
Extremity & $20(16.8)$ \\
Total & $119(100.0)$ \\
\hline
\end{tabular}

Data presented as $n(\%)$

were included. In addition to clinical data and descriptive epidemiological data, anthropometric measurements taken as a part of routine clinical practice for patients attending the various clinics such as weight, height (measured by stadiometer [Perspection Enterprises, USA]; otherwise, Seca 242 mechanical personal measuring rod [Seca, USA] recumbent for children $<2$ years of age) and chronological age were recorded. All personnel performing height and weight measurements were trained for the study. Measurements were performed in duplicate and repeated if discrepant measurements occurred. The mean value was recorded. The most recent NHANES III database (1999 to 2002) was used for all patients (NCHS - 2000 Centers for Disease Control and Prevention Growth Charts: USA (<www.cdc. gov/growthcharts/> accessed July 29, 2006).

Body mass index (BMI) was calculated using weight $(\mathrm{kg})$ divided by the square of height $\left(\mathrm{m}^{2}\right)$. For the analysis presented, BMI values were not converted into age-independent $z$-scores due to the lack of reference intervals for infants.

Casual blood pressure (BP) was measured from the right arm, resting and seated using an automated oscillometric device (Dinamap, USA), with the cuff covering two-thirds of the upper arm and the bladder encircling $>80 \%$ and $<100 \%$ of the upper arm circumference. Because only two readings were performed in some patients, the second reading was used for analysis. Casual BP percentile was calculated based on the 95th percentile for age, sex and height from the Fourth Report (1). For children between 17 and 18 years of age, the normative values for 17 -year-old children were used.

The computer program STAT Growth Charts for iPhone (Apple, USA) (Austin Physician Productivity, USA) was used for these calculations.

In addition to anthropometry, hemangioma size was recorded at each visit. All parents were counselled on the signs and symptoms of known side effects of propranolol and prednisone (hypoglycemia, hyperglycemia, limb cyanosis). They were asked to report these at each visit.

\section{Statistical analysis}

Data were collected into a spreadsheet (Excel, Microsoft Corporation, USA) for Mac version 14.3.1 (Apple, USA) and analyzed using GraphPad Prism for Mac version 5.0 (GraphPad, USA). Continuous numerical variables were analyzed for normal distribution using the D'Agostino \& Pearson omnibus test. Normally distributed data were expressed as mean \pm SD and data were compared using the Student's $t$ test. Data not normally distributed were expressed as median and interquartile range using the format 50 th percentile ( 25 th percentile, 75 th percentile) and, occasionally, the range was also stated. Change in height percentile per month was calculated for each group (controls, propranolol and corticosteroids) because treatment duration varied. The mean monthly change in height percentile was compared with a theoretical median of zero using the Wilcoxon signed-rank test. This process was then repeated for the calculation and analysis of change in BMI and systolic BP percentile per month.
TABLE 2

\begin{tabular}{lc} 
Hemangioma treatment initiated in patients seen at the \\
Children's Hospital, London Health Sciences Centre \\
(London, Ontario) from October 2007 to February 2012 \\
\hline Treatment \\
\hline No therapy initiated & $86(72.3)$ \\
Medical therapy & $18(15.1)$ \\
Propranolol & 7 \\
Steroids & 11 \\
Surgical therapy & $15(12.6)$ \\
Laser therapy & 6 \\
Surgical excision & 9 \\
Total & $119(100.0)$ \\
\hline
\end{tabular}

Data presented as $n(\%)$

\section{RESULTS}

A total of 123 patients (88 female [71.5\%]) were seen in the hemangioma clinic between October 2007 and February 2012. The median age was 0.8 years ( 0.3 years, 2.35 years) with a range from newborn to 15.9 years of age. One hundred nineteen patients had an IH (87 female [73.1\%]), one patient had a cavernous venous malformation and one had a portwine stain. There were two patients with other lesions such as lymphatic malformations. These patients had a total of 290 clinic visits, with one to seven appointments per child. Eighty-seven patients had one lesion, 16 had two and 20 had $>2$. Table 1 summarizes the anatomical location of $\mathrm{IHs}$ in the patient population. The treatment approach (conservative, surgical treatment and medical) is summarized in Table 2.

Of these, 64 patients were seen repeatedly (between two and seven times). Thirty-one were observed and received no treatment, six (18\%) underwent laser therapy, nine (27\%) received surgical resection and $18(55 \%)$ underwent medical therapy. Indications for medical therapy included obstruction of the visual field $(n=9)$, hemifacial involvement $(n=6)$ and recurrent ulceration/bleeding $(n=3)$. Of the 18 patients who underwent medical therapy, 11 received steroids and seven underwent propranolol treatment. Of the 11 patients who received steroids, two could not be analyzed because anthropometric measurements were not recorded. To assess the side effects of steroids and propranolol, the remainder of the analysis focused on the patients who received medical therapy with repeated anthropometry.

The follow-up for these 64 patients was variable. In the control group, the median follow-up was 364 days (119 days, 553 days); in the steroid group the median follow-up was 511 days (167 days, 835 days); and, in the propranolol group, the median follow-up was 372 days (243 days, 659 days). While the steroid group had a longer follow-up, this did not reach statistical significance ( $\mathrm{P}=0.529$ [Mann-Whitney]).

Prednisone was the corticosteroid used. The median dose was $5.0 \mathrm{mg} / \mathrm{kg} /$ day $(3.5 \mathrm{mg} / \mathrm{kg} / \mathrm{day}, 5.0 \mathrm{mg} / \mathrm{kg} / \mathrm{day})$. The median propranolol dose was $2.0 \mathrm{mg} / \mathrm{kg} /$ day $(1.0 \mathrm{mg} / \mathrm{kg} /$ day, $2.0 \mathrm{mg} / \mathrm{kg} /$ day $)$.

Treatment response to both corticosteroids and propranolol was excellent. The vascular abnormality decreased in size in 11 of 11 patients in the corticosteroid group and in six of seven patients in the propranolol group. A minimum $25 \%$ reduction in size was noted in all patients with visual field obstruction or ulceration/bleeding as a treatment indication. Interestingly, several patients on propranolol who were weaned off the medication after three months showed subsequent growth of the lesion. This resulted in restarting the drug and, in some cases, an increase in dose.

Median treatment duration in the steroid group was 133 days ( 45 days, 211 days), which was significantly shorter than that of the propranolol group with a median of 372 days ( 243 days, 659 days; $\mathrm{P}=0.0033$ [Mann-Whitney]).

The change in height percentile per month was analyzed. In the control group, the median change in height percentile per month was $0.0(-0.9,+0.4)$. In contrast, the steroid group had a negative height 


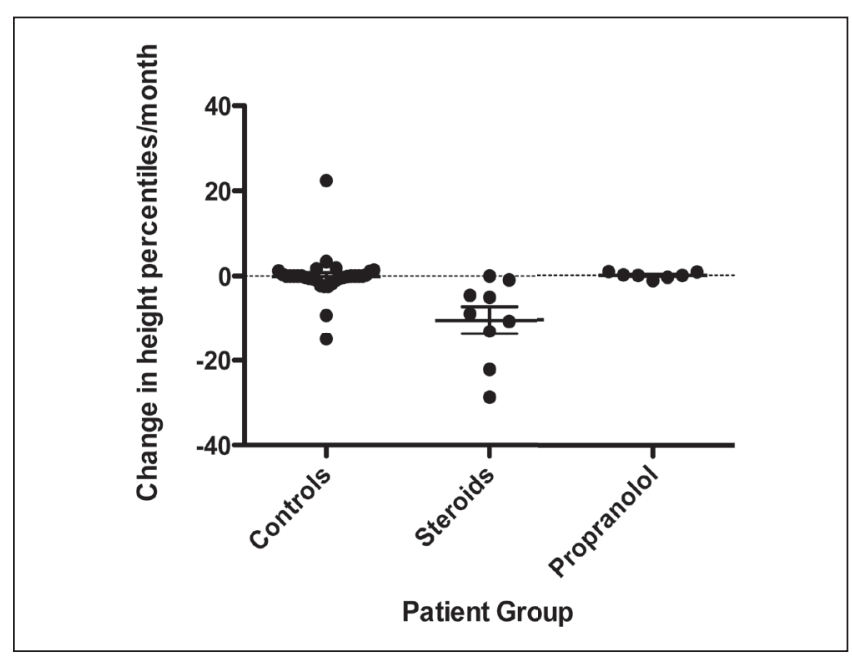

Figure 1) Change in height percentile per month in relation to hemangioma treatment initiated

velocity, with a median change in height percentile per month of -8.8 $(-17.6,-2.7)$. This was significantly different from zero $(\mathrm{P}=0.0078$ [Wilcoxon signed-rank test]). In the propranolol group, the median change in height percentile per month was $+0.06(-0.4,+0.8)$, which was not significantly different from zero (Wilcoxon signed-rank test). A comparison of the change in monthly height percentile for each treatment group is illustrated in Figure 1.

The change in BMI percentile per month was subsequently analyzed. In the control group, the median change in BMI percentile per month was $0.007(-0.049,+0.151)$, which was not significantly different from zero. In contrast, the steroid group had a negative height velocity, with a median change in BMI percentile per month of $-0.850(0.308,1.975)$; this was significantly different from zero $(\mathrm{P}=0.0039$ [Wilcoxon signed-rank test]). In the propranolol group, the median BMI percentile per month changed by $+0.004(-0.073$, +0.083 ), which was not significantly different from zero (Wilcoxon signed-rank test). A comparison of the change in monthly BMI percentile for each treatment group is shown in Figure 2.

Changes in systolic BP percentile per month were analyzed. In the control group, the median change in systolic BP percentile per month was $0.4(-0.1,+1.5) \mathrm{mmHg}$, which was not significantly different from zero. In the steroid group, the median increase in systolic BP percentile per month was $+1.7(-2.9,+7.9)$, although this did not reach statistical significance (Wilcoxon signed-rank test). In the propranolol group, the median systolic BP percentile changed by $-1.1(-4.7,-1.0)$, which was significantly different from zero $(\mathrm{P}=0.03$ [Wilcoxon signed-rank test]). A comparison of the monthly change in systolic BP percentile is shown in Figure 3. There was no hypotension observed in the propranolol group.

No cases of hypoglycemia, hyperglycemia or limb cyanosis were reported. Five patients had their blood glucose level tested, while in others, no venous blood sampling was pursued because they were asymptomatic.

\section{DISCUSSION}

The present study was a retrospective analysis of prospectively collected data from a new multidisciplinary vascular abnormality clinic in a single tertiary care centre. A large proportion of patients attended the clinic only once to obtain a second opinion. The majority of patients did not receive medical or surgical treatment. This was expected given the characteristic nature of hemangiomas (2). The proportion of patients that received medical treatment versus surgical treatment was slightly biased toward medical treatment. A similar proportion of patients received corticosteroids and propranolol, although there was a change over time as more data for propranolol

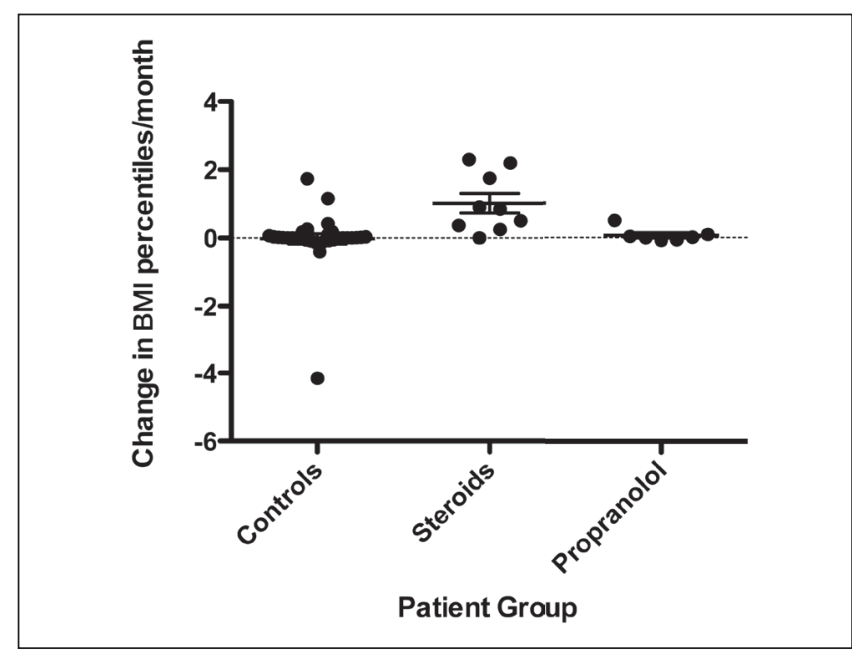

Figure 2) Change in body mass index (BMI) percentile per month in relation to hemangioma treatment initiated

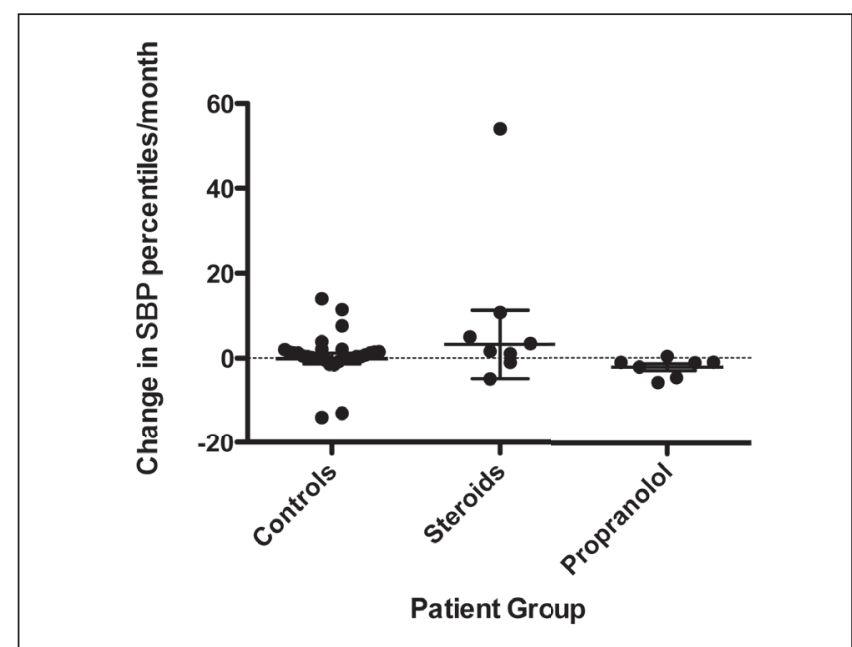

Figure 3) Change in systolic blood pressure (SBP) percentile per month in relation to hemangioma treatment initiated

became available. Not unexpectedly, corticosteroid therapy had a significant negative effect on height and increase in BMI. There was also an increase in BP, although this did not reach statistical significance. In contrast, propranolol therapy did not affect height or BMI, but resulted in a modest, yet statistically significant decrease in BP. No hypotensive values were recorded. The duration of therapy with propranolol was significantly longer.

For years, corticosteroids have been used as an effective medical treatment for hemangioma $(4,5)$. The mechanism of action in $\mathrm{IH}$ remains unclear, but increased mast cell number, decreased transcription of cytokines and enhanced transcription of the mitochondrial cytochrome b gene have been noted following steroid treatment (6). Our study observed a decrease in height percentile in children treated with steroids. The negative effect of oral steroids on pediatric height velocity is well documented $(7,8)$. This is assumed to be due to the greater susceptibility of an actively growing skeleton to the osteoblast-inhibiting effects of corticosteroids. For example, a sixpatient case series of bone biopsies from children receiving steroids for nephrotic syndrome found an inverse correlation between rate of bone formation and dose of prednisone at the time of biopsy (9). There is less evidence of decreased height velocity in the IH patient population. A previous study, however, supported a correlation between diminished gain of height with duration of steroid therapy and age at 
initiation of IH treatment (10). Another well-known side effect of pediatric oral steroids is increased BMI (8). Few, if any, studies to date report increased BMI following steroid treatment for hemangioma. We believe our study's careful collection and analysis of longitudinal anthropometric data allowed for detection of this negative side effect in our patients. We also detected an increase - although not statistically significant - in systolic BP in steroid-treated children. In a small study involving 37 patients with rapidly growing complicated hemangiomas (11), hypertension was reported in seven, and six were found to have borderline BP values. The limited number of patients in our corticosteroid-treatment group may have contributed to the lack of statistical significance observed in our study.

Since 2008, the beta-blocker propranolol has been shown to be effective in the treatment of IH (2). It is believed to both constrict existing blood vessels and inhibit new vascular growth in hemangiomas (12). It acts on beta-adrenergic receptors, decreasing the release of vascular endothelial growth factor and fibroblast growth factor (13).

Propranolol is a known antihypertensive with the following side effects reported in the IH patient population: cool extremities, irritability, lower gastrointestinal upset, emesis, hypotension, poor feeding, lethargy, bronchospasm and rash (14). To our knowledge, no previous studies have directly investigated the influence of propranolol on height and BMI in IH patients. Nevertheless, propranolol has been used since 2008 without report of adverse height or BMI change, which is consistent with our findings. We observed a mean propranolol treatment duration of 372 days, which is consistent with the current literature $(15,16)$.

\section{REFERENCES}

1. Fishman SJ, Mulliken JB. Hemangiomas and vascular malformations of infancy and childhood. Pediatr Clin N Am 1993;40:1177-200.

2. Craiglow BG, Antaya RJ. Management of infantile hemangiomas: Current and potential pharmacotherapeutic approaches. Paediatr Drugs 2013;15:133-8.

3. Bellardita L, Donegani S, Spatuzzi AL, Valdagni R. Multidisciplinary versus one-on-one setting: A qualitative study of clinicians' perceptions of their relationship with patients with prostate cancer. J Oncol Pract 2011;7:e1-5.

4. Bennett ML, Fleischer Jr AB, Chamlin SL, Frieden IJ. Oral corticosteroid use is effective for cutaneous hemangiomas: An evidence-based evaluation. Arch Dermatol 2001;137:1208-13.

5. Frieden IJ, Haggstrom AN, Drolet BA, et al. Infantile hemangiomas: Current knowledge, future directions. Proceedings of a Research Workshop on Infantile Hemangiomas. Pediatr Dermatol 2005;22:383-406.

6. Hasan Q, Tan ST, Gush J, Peters SG, Davis PF. Steroid therapy of a proliferating hemangioma: Histochemical and molecular changes. Pediatrics 2000;105:117-20.

7. Blodgett FM, Burgin L, Iezzoni D, Gribetz D, Talbot NB. Effects of prolonged cortisone therapy on the statural growth, skeletal maturation and metabolic status of children. N Engl J Med 1956;254:636-41.

8. Leonard MB, Feldman HI, Shults J, Zemel BS, Foster BJ, Stallings VA. Long-term, high-dose glucocorticoids and bone mineral content in childhood glucocorticoid-sensitive nephrotic syndrome. N Engl J Med 2004;351:868-75.
It is important to note the limitations to the present study. The data were acquired from a new multidisciplinary clinic at a single institution. Children presented to clinic by referral at variable ages. Unique characteristics of our patient population and/or institution-based treatment choices may not make our findings applicable to other settings. Additionally, due to the characteristic natural history of hemangioma, a limited number of patients received medical treatment and, thus, these preliminary results are based on a relatively small subset of patients.

The present study showed that the inclusion of $\geq 1$ pediatrician(s) in a vascular abnormality clinic is useful because a larger proportion of patients underwent medical treatment than surgical treatment. The observed results favour propranolol therapy, which is consistent with the current literature. The negative effect on height velocity and BMI related to corticosteroids cannot be offset by the shorter treatment duration. While the experience is limited, the present study, which carefully collected anthropometry and BP data from children, suggests that propranolol therapy at a median dose of $2.0 \mathrm{mg} / \mathrm{kg} /$ day results in a modest reduction in systolic BP without negative anthropometric effects. However, based on these preliminary findings, effective propranolol treatment duration is likely at least one year.

ACKNOWLEDGEMENTS: The authors thank Ms Marta Kobrzynski, research assistant to GF, for her expert editorial work on the revised manuscript.

SOURCE OF FUNDING: This database was established through research funds to MJR. There was no specific funding for the analysis.

9. Freundlich M, Jofe M, Goodman WG, Salusky IB. Bone histology in steroid-treated children with non-azotemic nephrotic syndrome. Pediatr Nephrol 2004;19:400-7.

10. Boon LM, MacDonald DM, Mulliken JB. Complications of systemic corticosteroid therapy for problematic hemangioma. Plast Reconstr Surg 1999;1041616-23.

11. Thédenat $B$, Léauté-Labrèze $C$, Boralevi $F$, et al. Blood pressure monitoring in infants with hemangiomas treated with corticosteroids. Ann Dermatol Venereol 2002;129:183-5.

12. Hogeling M, Adams S, Wargon O. A randomized controlled trial of propranolol for infantile hemangiomas. Pediatrics 2011;128:e259-66.

13. Sans V, Dumas de la Roque E, Berge J, et al. Propranolol for severe infantile hemangiomas: Follow up report. Pediatrics 2009;124:3.

14. Sharma VK, Fraulin FOG, Dumestre D, Walker L, Harrop AR. Beta-blockers for the treatment of problematic hemangiomas. Can J Plast Surg 20913;21:23-8.

15. Hermans DJ, Bauland CG, Zweegers J, van Beynum IM, van der Vleuten CJ. Propranolol in a case series of 174 patients with complicated infantile haemangioma: Indications, safety and future directions. Br J Dermatol 2013;168:837-43.

16. Parikh SR, Darrow DH, Grimmer JF, Manning SC, Richter GT, Perkins JA. Propranolol use for infantile hemangiomas: American Society of Pediatric Otolaryngology Vascular Anomalies Task Force practice patterns. JAMA Otolaryngol Head Neck Surg 2013;139:153-6. 